\title{
A COMPARATIVE SURVEY OF KNOWLEDGE OF ANTISEPTIC AND DISINFECTANT USE AND EFFECT OF INTERVENTION ON MEDICAL AND SURGICAL STAFF NURSES IN A TERTIARY CARE HOSPITAL
}

\author{
CHATTAR KANCHAN*, DABHADE SANGEETA, GHONGANE BALASAHEB
}

Department of Pharmacology, B. J. Medical College, Pune, Maharashtra, India. Email: chattardrkanchan@gmail.com

Received: 11 July 2017, Revised and Accepted: 01 October 2017

\section{ABSTRACT}

Objective: The study was carried out to find the knowledge and awareness of medical and surgical section nurses about the use of antiseptic and disinfectants and the immediate and late impact of an educational intervention like seminar and workshop in the knowledge of nurses.

Method: This is a questionnaire-based pre- and post-test cross-sectional study. 200 nurses (100 working in medical wards and 100 working in surgical wards and operation theater) were selected using random number sampling method. First, a pretest was given. Then, an educational intervention in the form of seminar was carried out and posttest was given. One more test was carried out 1 month after posttest to check retention of knowledge by nurses.

Result: In both medical and surgical pretest, most of the questions answered correctly were in below $25 \%$ response. While in posttest number of the questions answered correctly was increased and a maximum number of the questions solved correctly were between $50-75 \%$ and $75-100 \%$. Individual response in the pretest both medical and surgical nurses showed that a maximum number of nurses have responses between $25-50 \%$ and $50-75 \%$ while response rate has increased in posttest where maximum number of responses were between $75 \%$ and $100 \%$.

Conclusion: Our study suggests that educational intervention has positive impact on the knowledge of nurses. There is a need to carry out such educational interventions periodically which will be helpful for better retention of knowledge by nurses.

Keywords: Educational intervention, Pretest, Posttest, Hospital-acquired infection.

(c) 2018 The Authors. Published by Innovare Academic Sciences Pvt Ltd. This is an open access article under the CC BY license (http://creativecommons. org/licenses/by/4. 0/) DOI: http://dx.doi.org/10.22159/ajpcr.2018.v11i1.21218

\section{INTRODUCTION}

Antiseptic and disinfectants are chemical agents that inhibit or destroy microorganisms on living tissue (antiseptics) and inanimate surfaces and objects (disinfectants). They are a crucial part of infection control practices [1].

Hospital-acquired infection (HAI) is one of the important concerns because it takes a heavy toll on patients and their families as it causes illness, prolongs hospital stays, reduces the quality of life, increases the potential of disabilities, increases the resistance of the microbes to antimicrobials, as well as leading to excess costs, and sometimes death of the patient.

Education and training of healthcare workers about standard infection control and strict adherence by healthcare staff to aseptic practice can reduce the extent of risks of HAI [2].

Rational use of disinfectants leads to a substantial reduction in HAI and requirement of disinfectants [3]. For the appropriate use of disinfectants, adequate knowledge of various types of disinfectants and the categories of medical and surgical devices for disinfection, also the risk of infection associated with improper disinfection is necessary. Nurses play a vital role in supervising disinfection in hospitals. Hence, they are an important target group for educational interventions for rationalization of disinfectant use. Their knowledge and awareness have a great impact on the use of disinfectants in hospitals. Hence, targeting nurses for educational interventions that aim at rationalizing disinfectant use is important. Regular assessment of the effectiveness of the infection prevention and control program and its impact on practices in the healthcare setting is necessary. Different studies done previously have been shown that educational interventions have positive impact on the disinfectant practices and there is a need to carry out such studies [4-6]. Thus, we planned a study to find the knowledge and awareness of medical and surgical section nurses about the use of antiseptic and disinfectants and the immediate and late impact of an educational intervention like seminar and workshop in the knowledge of nurses.

\section{METHODS}

This is a questionnaire-based pre- and post-test cross-sectional study. This was conducted at a tertiary care government hospital after obtaining approval from Institutional Ethics Committee. Pilot study for the validation of questionnaire was carried out and only validated questions were included in the final questionnaire.

Written informed consent was taken from 200 nurses (100 working in medical wards and 100 working in surgical wards and operation theater) who were willing to participate in the study. Nurses not willing to participate in the study were excluded. For selection, random number sampling method was used for the nurses willing to participate in the study. The questionnaire contained 20 questions based on knowledge of nurses about different antiseptics and disinfectants such as their level of disinfection (high, intermediate, and low), their uses, dilution to be used for different purposes, any special precautions to be taken while using antiseptics or disinfectant, storage conditions, and different hand hygiene methods used for different purposes. First, a pretest was given. Then, an educational intervention in the form of power point presentation was carried out and posttest was given. One more test was carried out 1 month after posttest to check retention of knowledge. The responses of questions from pretest, posttest, and a test carried out after 1 month to check retention of knowledge were compared. For correct response, 1 mark was given while 0 mark was given for 
wrong or unattempted question. Percentage of marks obtained by each nurse and percentage of nurses responded correctly to each question was calculated. The responses were graded according to UCG grading system [7].

\section{RESULTS}

The results of 100 nurses from medical wards (labeled as medical pretest and posttest) and 100 nurses from the surgical side (labeled as surgical pretest and posttest) were as follows (Figs. 1 and 2).

\section{DISCUSSION}

It was observed that the number of correct responses was more from medical pretest than surgical pretest and there was improvement responses in posttest of both medical and surgical nurses.

In both medical and surgical pretest, a maximum number of the questions answered correctly were in below $25 \%$ response. While in posttest number of the questions answered correctly was increased and a maximum number of the questions solved correctly were between $50-75 \%$ and $75-100 \%$. Individual response in the pretest both medical and surgical nurses showed that maximum number of nurses have response between 25 and $50 \%$ and $50-75 \%$ while response rate has increased in posttest where maximum number of responses were between $75 \%$ and $100 \%$.

In the pretest, the nurses from both medical and surgical side have good knowledge about what the antiseptic and disinfectant means, the uses of potassium permanganate and povidone-iodine, agent to be used for cleaning after a spillage of blood and blood products, activated solution of glutaraldehyde should be used in how many days, etc. Awareness about agent used for cleaning after spillage of blood and blood products is may be due to good knowledge of nurses about diseases transmitted from contaminated blood and blood products such as HIV, and hepatitis B. As glutaraldehyde is the only high level and costly disinfectant available at the study site, thus, nurses may be more aware about it. Questions related to OT fumigation techniques like agent used for neutralization of OT after fumigation by formalin is answered correctly by more number of surgical staff. Knowledge about neutralization is important because if neutralization is not done after fumigation with formalin, then, even though the results of the swabs taken from OT to check any residual microorganisms after fumigation comes negative, there are chances of spread of infection. Different properties of the chloroxylenol (Dettol) such as uses, solubility in water, and duration of activity after mixing with water are answered well by medical staff. Different hand hygiene methods used in different situations (e.g., before giving injection, after exposure to blood) were answered fairly by medical staff than surgical staff. Environmental surfaces like bedside table, stethoscope could potentially contribute to cross-infection by contamination of healthcare personnel from hand contact with contaminated surfaces, medical equipment [8]. Combination of Cetrimide + Chlorhexidine gluconate has broad antimicrobial activity against bacteria, fungi, enveloped viruses, and protozoa. Thus, it can be used for washing of hands for better control of spread of infection [9].

While questions related use of the different disinfectants and concentration used for different purposes had poor response in both groups.

In the posttest, there is an overall increase in response similar to study done by Burute et al., [10] in both medical and surgical nurses except for the questions like uses of phenol, concentration of disinfectant to be used for different uses and special precautions to be taken while using glutaraldehyde. Knowledge about uses of phenol is important because it can be used for disinfection of urine, sputum, floor cleaning, etc., which is an important measure to prevent contamination of soil and spread of tuberculosis, etc. Hospital floors become contaminated

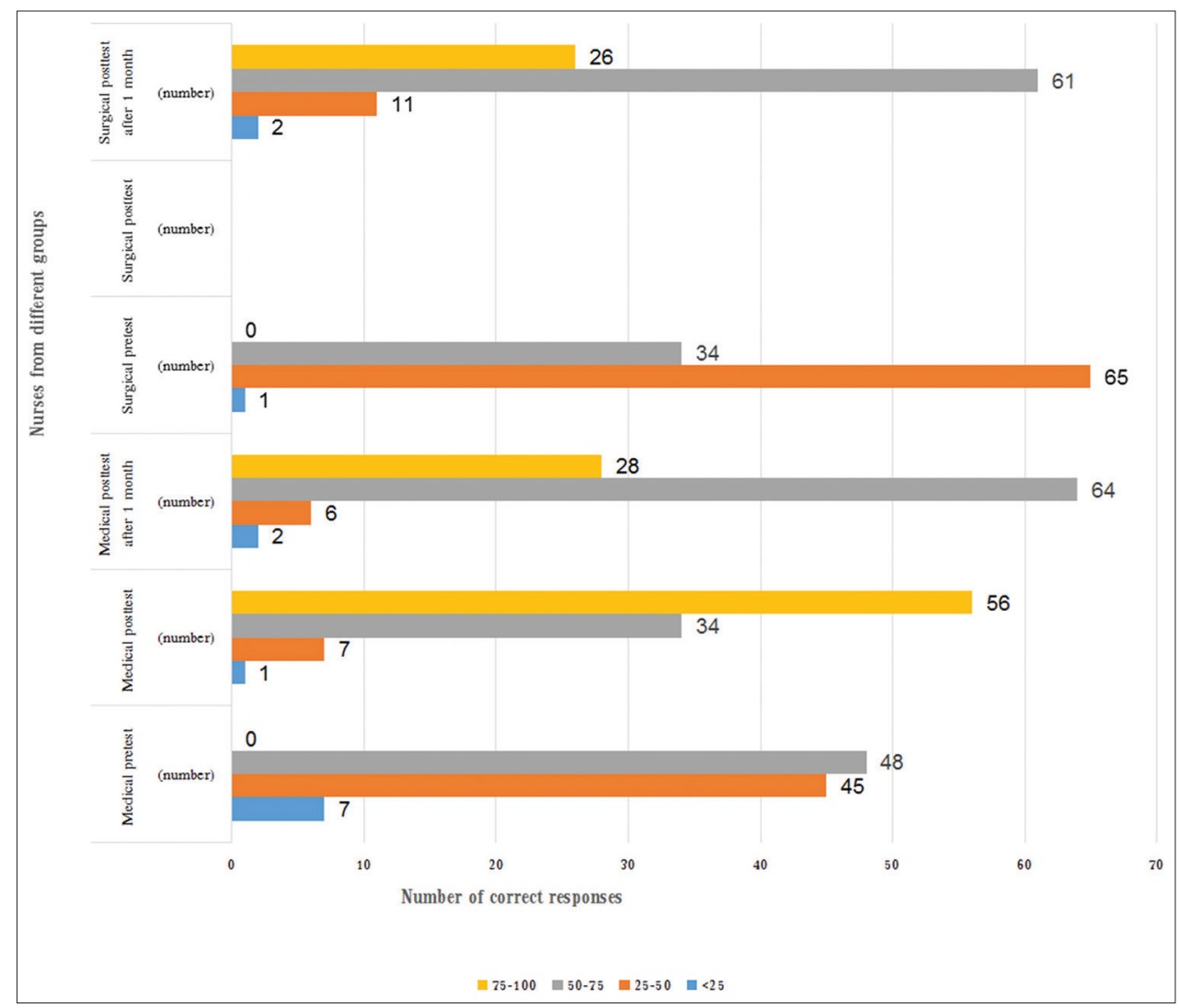

Fig. 1: Question wise response by nurses $(n=100)$ 


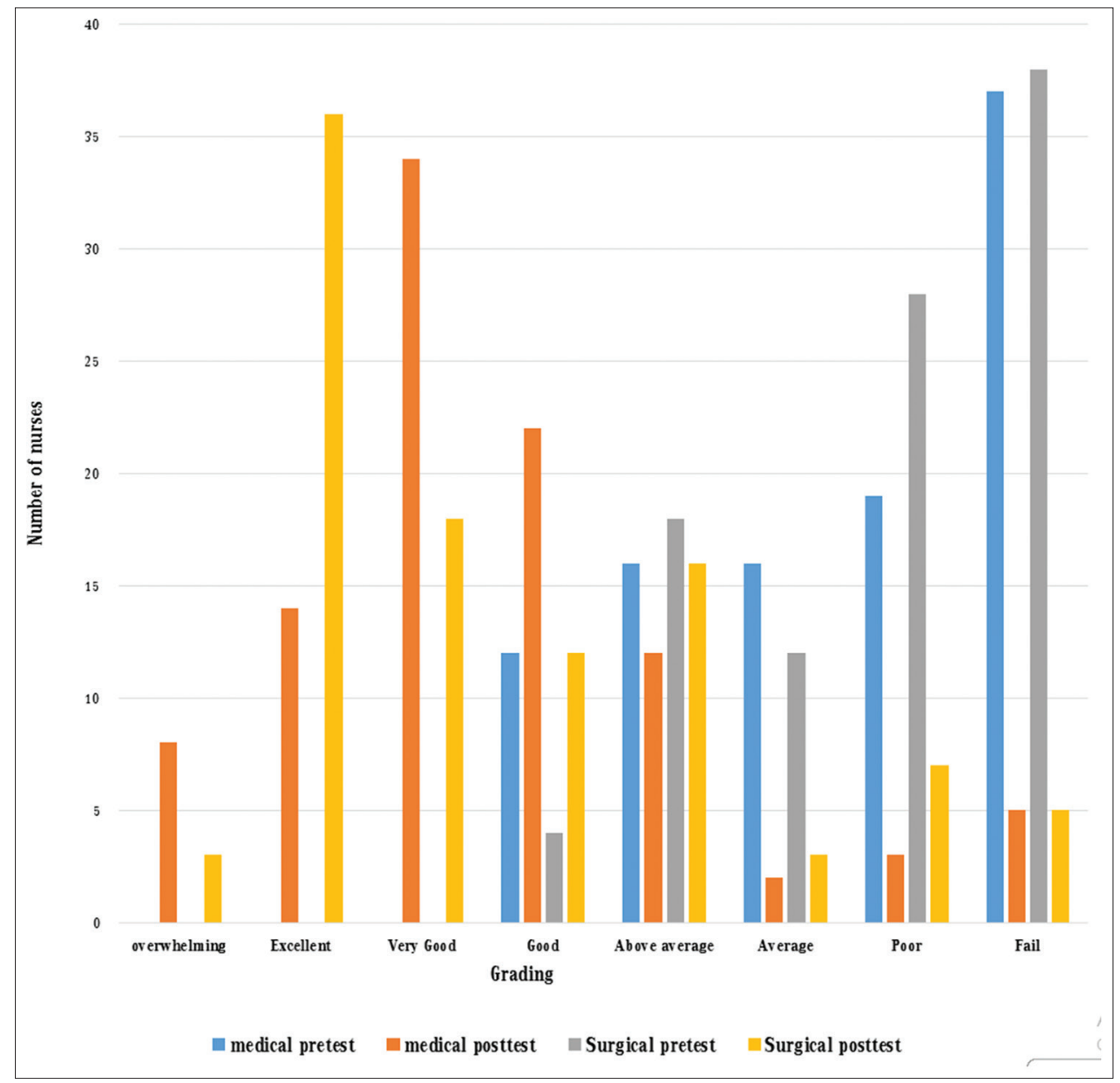

Fig. 2: Grading according to marks obtained by nurses $(n=100)$

with microorganisms from settling airborne bacteria: By contact with shoes, wheels, and other objects and occasionally by spills. The removal of microbes is important in controlling health-care-associated infections. In an investigation of the cleaning of hospital floors, the use of soap and water ( $80 \%$ reduction) was less effective in reducing the numbers of bacteria that were a phenolic disinfectant [11]. The widespread use of antiseptic and disinfectant products has prompted some speculation on the development of microbial resistance. Concentration of disinfectant used for different purposes is important because antiseptics - resistant microbial strains have developed because of the lack in standardization of some factors such as criteria for the use of chemicals agents, specifications in the labels of available products, and lack of well-trained personnel. Microbial resistant to some antiseptics has become a serious public health problem. Thus, selection, use, and control of the effectiveness of the antiseptics are needed [9]. Alternatively, many herbal products having wide range of antimicrobial properties can be used [12,13]. As healthcare personnel is at high risk of health hazards from different chemical used, knowledge about not only uses but special precautions to be taken while using disinfectants is important for them.

\section{CONCLUSION}

Our study suggests that educational intervention has positive impact on the knowledge of nurses similar to other studies $[10,14]$. There is a need to carry out such educational interventions periodically as in the test carried out after 1 month showed good retention of knowledge by nurses. Such interventions will help to rationalize the use of antiseptics and disinfectants, which will be helpful both economically and to improve the quality of disinfection procedures carried out in hospitals.

\section{REFERENCES}

1. Rutala WA, Weber DJ. Guideline for Disinfection and Sterilization in Healthcare Facilities. Atlanta (GA): Centers for Disease Control and Prevention; 2008. p. 1-158

2. Avachat S, Phalke D, Zambare M, Phalke V. Impact of sensitization workshop on knowledge and awareness of hospital-acquired infection among nurses of a teaching hospital in India. Southeast Asian J Public Health 2012;2:77-9.

3. Agarwal V, Gharpure K, Thawani V, Makhija S, Thakur A, Powar R. Economic impact of interventional study on rational use of antiseptics and disinfectants in Super Speciality hospital of Nagpur. Indian J Pharmacol 2008;40:78-83.

4. Vij A, Williamson SN, Gupta S. Knowledge and practice of nursing staff towards infection control measures in a Tertiary Care hospital. J Acad Hosp Adm 2001;13:7-12.

5. Abdallah SA, Al-Shatti L, Al-Awadi B, Al-Hammad N. Disinfectants use awareness among college of nursing students and nurses in some healthcare settings, Kuwait. Middle East J Sci Res 2012;12:964-9.

6. Oli AN, Nweke JN, Ugwu MC, Anagu LO, Oli AH, Esimone CO. Knowledge and use of disinfection policy in some government hospitals in South-East, Nigeria. Br J Med Med Res 2013;3:1097-108.

7. Available from: http://www.indiatoday.intoday.in/education/story/ ugc-order--all-universities-must-have-grading-system-semestersfrom-2015-16/1/412850.html. [Last accessed on 2017 Mar 23].

8. Cozad A, Jones RD. Disinfection and the prevention of infectious disease. Am J Infect Control 2003;31:243-54.

9. Olorode OA, Bamigbola EA, Ogba OM. Antimicrobial activities of chlorhexidine gluconate and cetrimide against pathogenic microorganisms isolated from slaughter houses in rivers state, Nigeria. Int J Pharm Pharm Sci 2015;7:322-8.

10. Burute SR, Murthy MB, Ramanand SJ, Pore SM, Karande VB, Akat PB. Immediate impact of an educational intervention on knowledge of use 
of disinfectants in nurses. Int J Basic Clin Pharmacol 2014;3:507-11.

11. Ayliffe GA, Collins BJ, Lowbury EJ. Cleaning and disinfection of hospital floors. Br Med J 1966;2:442-5.

12. Amala VE, Jeyaraj M. Determination of antibacterial, antifungal, bioactive constituents of Triphala by FT-IR and GC-MS analysis. Int J Pharm Pharm Sci 2014;6:123-6.
13. Balijepalli1 MK, Buru AS, Sakirolla R, Pichika MR. Cinnamomum genus: A review on its biological activities. Int J Pharm Pharm Sci 2017;9:1-11.

14. Sessa A, Di Giuseppe G, Albano L, Angelillo IF; Collaborative Working Group. An investigation of nurses' knowledge, attitudes, and practices regarding disinfection procedures in Italy. BMC Infect Dis 2011;11:148. 